\title{
Performed Administrative Activity Variance Reason
}

National Cancer Institute

\section{Source}

National Cancer Institute. Performed Administrative Activity Variance Reason. NCI

Thesaurus. Code C93901.

A description of the variance of an administrative activity. 